Int. J. Curr. Res. Med. Sci. (2017). 3(3): 62-71

\begin{tabular}{|c|c|c|c|}
\hline International Journal of Current Research in & \\
Medical Sciences & ISSN: 2454-5716 \\
\hline IJCRMS & P-ISJN: A4372-3064, E -ISJN: A4372-3061 \\
WWW.ijcrims.com & \\
\hline
\end{tabular}

\title{
Incidence, etiological risk factors and outcome of glucose-6 phosphate dehydrogenase deficiency (G6PDD) among neonates presenting with hyperbilirubinemia in tertiary care hospital, Punjab.
}

\author{
*Karnail Singh, **Palwinder Singh , ***Munish Sagar,****Vijay Mehra, \\ ******N.S.Neki \\ *Professor of Paediatrics, **Associate Professor of Paediatrics,***Junior Resident Paediatrics, Govt. \\ Medical College, Amritsar, 143001,India \\ ****Associate Professor of Pathology, Govt. Medical College, Amritsar, 143001, India \\ ******Professor of Medicine, Govt. Medical College, Amritsar, 143001, India \\ Corresponding Author: Dr. Palwinder Singh, Associate Professor, Dept. of Paediatrics, Govt. Medical \\ College, Amritsar, 143001, India \\ E-mail: drpalwinderrajput@gmail.com
}

\begin{abstract}
Objectives: The aim of this study was to analyse the incidence and outcome of G6PD deficiency(G6PDD) among neonates presenting with hyperbilirubinemia and to evaluate other etiological risk factors associated with hyperbilirubinemia.

Methods: This was a prospective study conducted on jaundiced neonates, over a period of 6 months. Perinatal history was taken. Laboratory parameters included serum bilirubin, haemoglobin, peripheral blood film and blood groups. Treatment modality and outcome was noted during the hospital stay.

Results: The incidence of G6PDD was found to be $4.16 \%$ and only in males. Total serum bilirubin level in G6PD deficient cases was (mean $=22.72 \pm 5.1$ ), which is significantly higher when compared with other causes of jaundice(Physiological, Cephalhematoma, Idiopathic) except ABO and Rh incompatability. Physiological jaundice was the most common cause of neonatal jaundice (45.83\%).

Conclusions: G6PDD is one of the common causes of most severe form of neonatal jaundice with higher hemoglobin levels and significant hyperbilirubinemia predominantly in males and can present with jaundice earlier than other etiologies . Babies with G6PDD can present earlier and can have serious consequences.
\end{abstract}

Keywords: G6PDD, Neonates, Hyperbilirubinemia, Serum bilirubin. 


\section{Introduction}

Neonatal jaundice is the commonest abnormal physical finding in the first week of life which affects nearly $70 \%$ term and $80 \%$ preterm infants [1]. It is associated with various known physiological and pathological conditions with varying outcomes. The wide variety of risk factors that have been associated with hyperbilirubinemia in newborns include prematurity, previous sibling with jaundice, $\mathrm{ABO}$ incompatibility, $\mathrm{Rh}$ incompatability, inadequate breast feeding, infections and birth trauma [2]. Glucose-6 phosphate Dehydrogenase deficiency (G6PDD), is probably the most common erythroenzymopathyaffecting $10 \%$ of the world population (400 million world wide) $[3,4,5]$. The prevalence rate varies from $0-27 \%$. Neonates with G6PDD develop jaundice which when severe and if untreated could give rise to kernicterus, a well known cause of death and poor neurodevelopmental outcome [6 ]. In later life the disease can cause acute haemolytic crisis on exposure to certain agents/drugs which trigger or sensitize the red cells leading to significant morbidity and mortality in childhood. As primary prevention is not available, the only way to avoid morbidity is to recognize such children early in life and prevent morbidity and mortality at its earliest[7]. This study was conducted to evaluate the incidence of G6PDD among the neonates suffering from neonatal hyperbilirubinemia, etiological factors other than G6PDD, if any, associated with neonatal hyperbilirubinemia and to study the outcome of G6PDD among the neonates suffering from hyperbilirubinemia.

\section{Materials and Methods}

A total of 210 neonates, who presented to us with hyperbilirubinemia and clinical jaundice were included in the study. The study was approved by institutional research ethical committee and was in accordance to the tenets set forth in Declaration of Helsinki. An informed consent was taken from the parents of the children prior to the start of the study. Out of a total of 210, 42 neonates with sepsis and conjugated hyperbilirubinemia (direct serum bilirubin $>20 \%$ of the total) were excluded from the study. The study was conducted for the period of 6 months, from April 2016 September 2016.

A detailed history including maternal antenatal history was recorded with special attention to the drugs which can produce hemolysis in G6PD(Glucose-6 phosphate Dehydrogenase) deficients, any sign of toxemia, antepartum haemorrhage, intrauterine infections, prolonged rupture of membranes, leakage per vaginum $>18$ hours and radiation exposure. Regarding labour, whether spontaneously or artificially induced with oxytocin (which increases the chances of hemolysis in newborns) was noted, including duration of labour and method of delivery. History of fetal distress, delayed cord clamping, APGAR score at 1, 5 and 10 minutes and details of resuscitation if any was noted in every newborn with its date and time of birth.

In all newborns, history of jaundice, its day of onset, peak bilirubin level, age at peak bilirubin level, duration of hospitalization, management (whether phototherapy or exchange transfusion) and outcome were noted. The mother or attendant were also questioned about any evidence of lethargy, refusal to feed, convulsions, diarrhea or vomiting in newborn including questioning about feeds i.e. whether they were breastfed or top fed. Relevant detailed family history was recorded. Detailed general examination of the neonate was carried out as heart rate, respiratory rate, temperature, behaviour i.e. either alert and active, irritable or lethargic, skin examination for colour( cyanosis or pallor), extent of jaundice (over face, upto thorax and sole). Skull, face, spine, hands and feet were also examined. Cry were noted whether normal or high pitched. Anthropometric measurements as weight, length, head and chest circumference were recorded in all newborns. Abdomen, cardiovascular, respiratory and central nervous system were thoroughly examined. Various laboratory investigations Hemoglobin percentage,Serum bilirubin (Total, Direct, Indirect), G6PD estimation, Blood group (ABO and $\mathrm{Rh}$ ) of baby and mother, Peripheral blood film(PBF) were performed for all cases. Direct coomb test, Reticulocyte count, Chest X-ray, Serum electrolytes, Cerebro spinal fluid examination, Blood sugar, Renal function, 
Prothrombin time, Sepsis profile which included Total leucocyte count, Differential leucocyte count, Platelet count, C-reactive protein, Band cell ratio, Blood culture and sensitivity were performed as and when required.

Methods used for estimation of Serum bilirubin and G6PD enzyme were done by Diazo method of Pearlman and Lee and UV kinetic method" respectively. The blood sample used were unhaemolysed serum or plasma as it causes falsely low results. Samples were protected from bright light as bilirubin is photolabile and were stored as refrigerated for 3 days.

\section{Interpretation of the test values}

We standardized the G6PD activity in units/g $\mathrm{Hb}$ at 37 degree celcius temperature.

It was between 6-15 units/g $\mathrm{Hb}$. Neonates with values less than 6 units/gm $\mathrm{Hb}$ were considered as positive for G6PDD.

\section{Statistical analysis}

Data were initially entered into an excel spreadsheet and then transferred to SPSS software
(Statistical Package for Social Sciences, version 22.0,SPSS Inc, Chicago, IL). Data was expressed in term of mean $\pm \mathrm{SD}$. Categorical variables were presented as absolute numbers and percentages. The comparison of day of appearance of jaundice and total bilirubin levels between G6PDD and other causes of neonatal jaundice was performed using unpaired Student's t-test. $\mathrm{P}$ value $<0.05$ was considered statistically significant.

\section{Results}

Among 168 neonates which were included in the present study, 115(68.45\%) were males and $53(38.55 \%)$ were female. Among various etiologies of neonatal jaundice, physiological jaundice was found to be the most common cause of neonatal jaundice (45.83\%) where as G6PDD accounted for 7 cases $(4.16 \%)$. Cephalhematoma was the least common etiological factor encountered in the present study [Table 1/Fig-1].

Table 1 Distribution of neonatal Hyperbilirubinemia according to etiology

\begin{tabular}{|c|c|c|}
\hline Etiology & Number & $(\%)$ \\
\hline Physiological & 77 & 45.83 \\
\hline ABO Incompatability & 30 & 17.85 \\
\hline Rh Incompatability & 12 & 7.14 \\
\hline G6PD deficiency & 7 & 4.16 \\
\hline Cephalhematoma & 3 & 1.78 \\
\hline Idiopathic & 39 & 23.21 \\
\hline
\end{tabular}




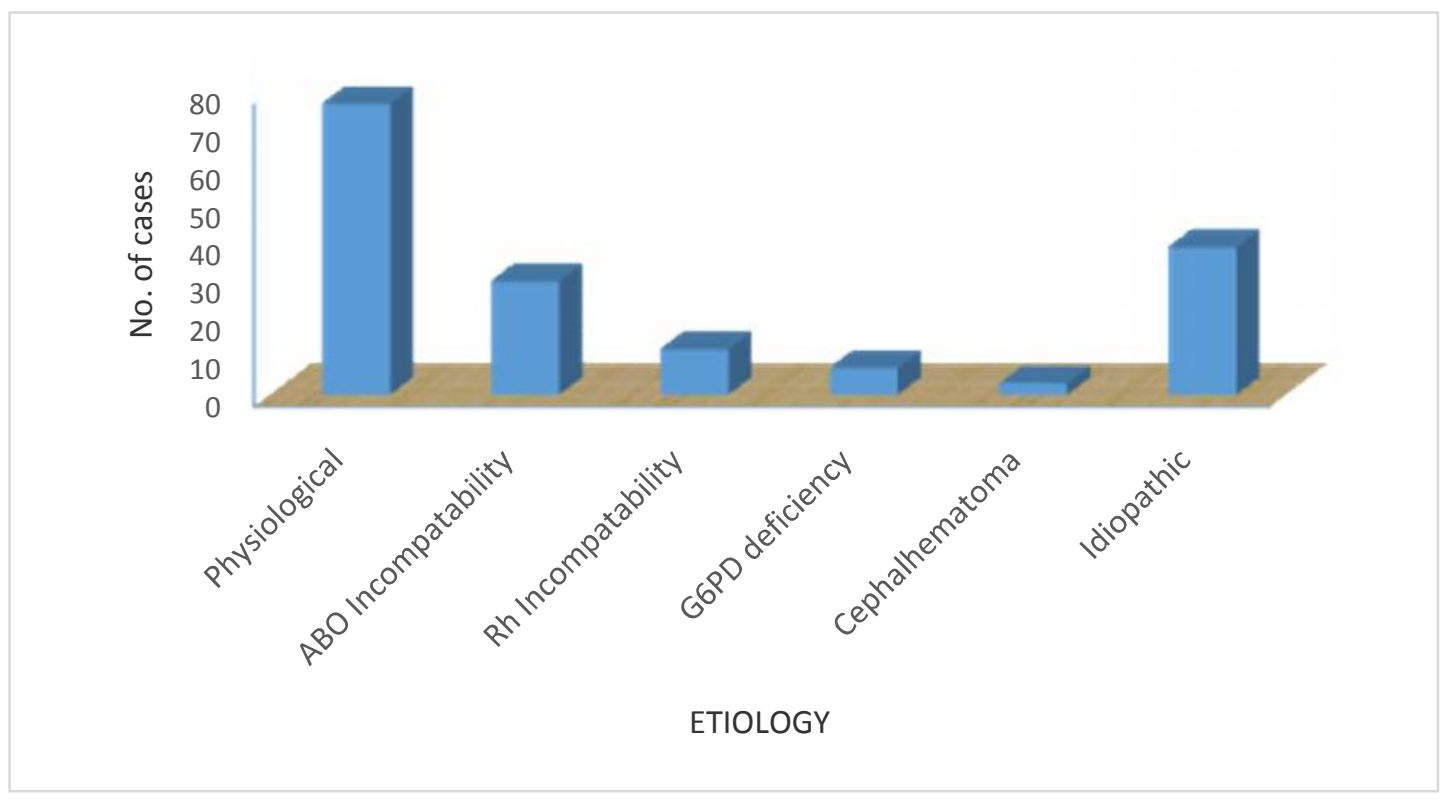

Figure 1 Shows distribution of neonatal hyperbilirubinemia according to etiology.

Out of the 23 cases who developed jaundice on day 1 of life, highest number belonged to ABO incompatability $(n=11)$. Rest of the cases with ABO incompatability $(n=19)$ developed jaundice between 1-3 days. 8 cases $(66.66 \%)$ out of 12 cases of $\mathrm{Rh}$ incompatability developed jaundice on day 1 of life and rest 4 cases $(33.33 \%)$ developed jaundice on day 2 of life.

Out of 7 cases of G6PDD, 4 cases developed clinical jaundice between 1-3 days. Mean period of appearance of clinical jaundice in G6PDD was $2.00 \pm 1.09$ days whereas for physiological jaundice it was $2.88 \pm 0.76$ days. Jaundice was more severe in cases due to $\mathrm{Rh}$ incompatability (mean serum bilirubin level $=21.56 \pm 4.33 \mathrm{mg} / \mathrm{dl}$ ) and G6PDD (mean serum bilirubin level=22.72 \pm 5.1) than other causes of neonatal jaundice. Highest number of cases of neonatal jaundice had hemoglobin levels between 14$16 \mathrm{gm} / \mathrm{dl}$. Among G6PD deficient cases hemoglobin level was between 14-16 in 5 cases, between $12.1-14 \mathrm{gm} / \mathrm{dl}$ in 1 case and $<12 \mathrm{gm} / \mathrm{dl}$ in 1 case.

The incidence of G6PDD in the present study was found to be $7(4.16 \%)$. It was the $4^{\text {th }}$ common cause of neonatal jaundice excluding the idiopathic cause. G6PDD was encountered only in males. Out of 7 cases with G6PDD, 5(71.42\%) cases had serum bilirubin levels $>20 \mathrm{mg} / \mathrm{dl}$ and 2 $(28.57 \%)$ cases were between $15-20 \mathrm{mg} / \mathrm{dl}$ with mean of $22.72 \mathrm{mg} / \mathrm{dl}$. Out of 7 newborns with G6PDD, 4 were weighing $\geq 2.5 \mathrm{~kg}$ and 3 newborns $<2.5 \mathrm{~kg}$ [Table 2 /Fig-2]. The difference between the two groups was statistically non-significant $(\mathrm{P}=0.948)$. In non deficient group 94 cases weighed $\geq 2.5 \mathrm{~kg}$ and 67 cases $<2.5 \mathrm{~kg}$. But the difference between the two groups was statistically non-significant ( $\mathrm{P}=0.237)$.

Table 2 Day of appearance of jaundice in relation to etiology

\begin{tabular}{|c|c|c|c|c|}
\hline Etiology & $<1$ Day & $1-3$ Days & $>3$ Days & $\begin{array}{c}\text { Mean } \pm \text { S.D } \\
\text { (Days) }\end{array}$ \\
\hline Physiological & 0 & 59 & 18 & $2.88 \pm 0.76$ \\
\hline ABO Incompatability & 11 & 19 & 0 & $1.73 \pm 0.62$ \\
\hline Rh Incompatability & 8 & 4 & 0 & $1.33 \pm 0.49$ \\
\hline Cephalhematoma & 0 & 2 & 1 & $3.33 \pm 0.57$ \\
\hline G6PD deficiency & 2 & 4 & 1 & $2.00 \pm 1.09$ \\
\hline Idiopathic & 2 & 32 & 5 & $2.69 \pm 0.76$ \\
\hline
\end{tabular}


Int. J. Curr. Res. Med. Sci. (2017). 3(3): 62-71

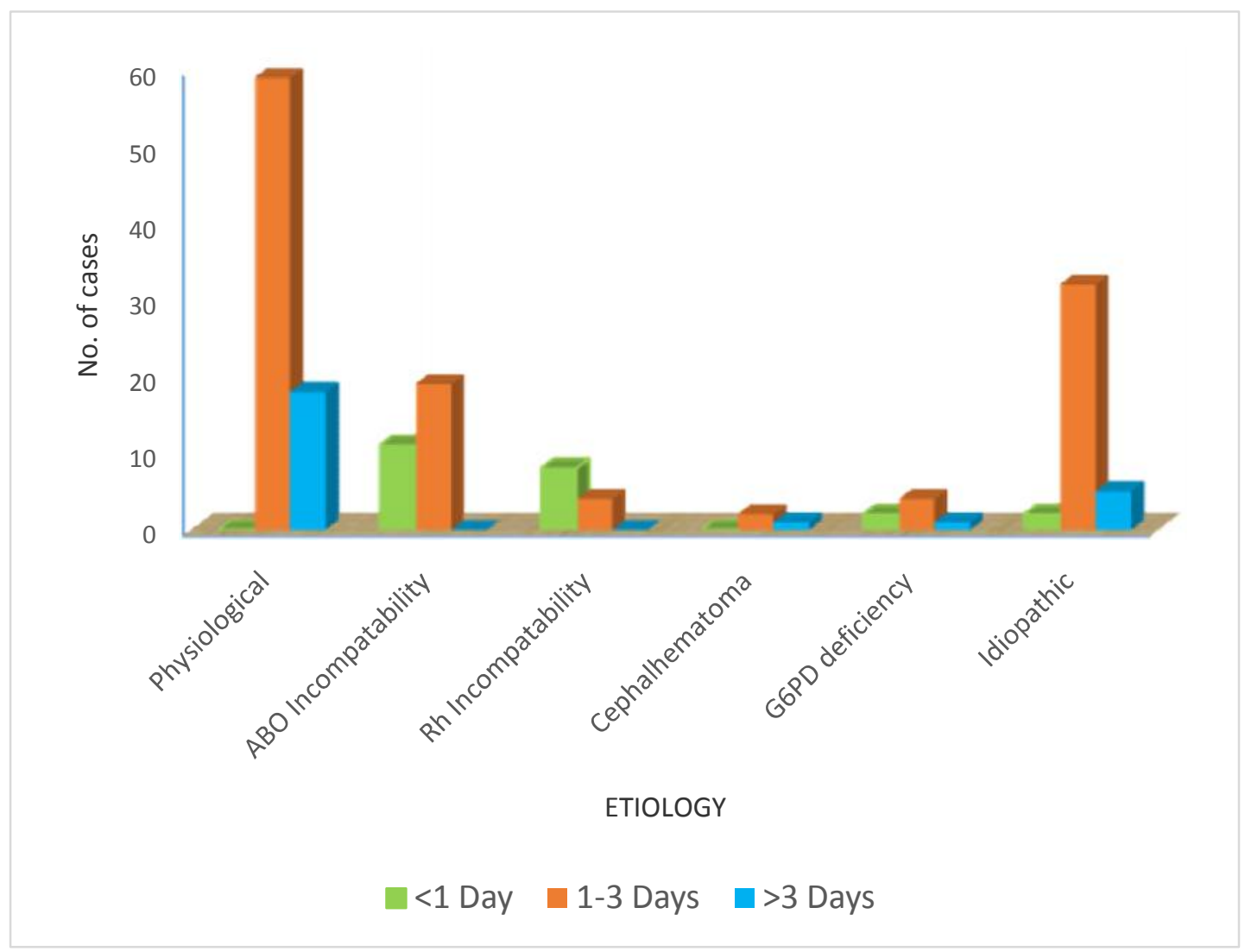

Figure-2 Shows Day of appearance of jaundice in relation to etiology

The mean age was $33.86 \pm 0.18$ weeks for pre term $(<37$ weeks) and $38.5 \pm 1.11$ weeks for term ( $>37$ weeks) new borns. Preterm neonates in the study accounted for $38 \% \quad(n=54)$, whereas $62 \%(\mathrm{n}=104)$ were term neonates. Although more (4 out of 7 ) G6PD deficient cases were term babies. In non-deficient group, 100(96.15\%) cases were term and $61(95.31 \%)$ were preterm. There was no statistical significance when the distribution of G6PDD in preterm and term babies was compared $(\mathrm{P}=0.79)$. All the cases with G6PDD had anisopoikilocytosis . $71.4 \%$ showed Heinz bodies and $37.5 \%$ showed fragmented RBCs. 1 (14.2\%) out of 7 showed spherocytes. This signifies an ongoing hemolysis in all the cases of G6PDD.

5 out of 7 cases of G6PDD had hemoglobin levels $>14 \mathrm{~g} / \mathrm{dl}$, suggesting that hemolysis was not the only cause of jaundice in G6PDD. 77 (45.8\%) cases of neonatal hyperbilirubinemia required only phototherapy, while $24(14.2 \%)$ cases also required exchange transfusion in addition to phototherapy. In G6PD deficient cases, 4 (57.1\%) required phototherapy and $3(42.8 \%)$ required exchange transfusion also. Mean serum bilirubin level in G6PDD was $22.72 \pm 5.1 \mathrm{mg} / \mathrm{dl}$, while in $\mathrm{Rh}$ incompatability and $\mathrm{ABO}$ incompatability, it was $21.56 \pm 4.33$ and $19.93 \pm 4.04 \mathrm{mg} / \mathrm{dl}$ with their statistically non-significant difference respectively $(\mathrm{P}=0.08,0.41)$. In rest of the cases due to other etiological factors like physiological, cephalhematoma and idiopathic the difference in the serum bilirubin level were statistically significant respectively $(\mathrm{P}=0.00,0.03,0.001)$. In G6PDD the mean days of appearance of jaundice were $2.00 \pm 1.09$ and the difference was not found to be statistically significant ( $\mathrm{P}$ value $>0.05$ ) when compared to those infants who had ABO and $\mathrm{Rh}$ Incompatability with $\mathrm{P}$ value of ( 0.41 , 0.08 ) respectively. In other causes of neonatal hyperbilirubinemia like physiological, cephalhematoma and idiopathic, the difference in the day of appearance of jaundice was statistically significant with $\mathrm{P}$ value of $(0.01,0.049,0.05)$ respectively [Table $3 /$ Fig-3]. 
Int. J. Curr. Res. Med. Sci. (2017). 3(3): 62-71

Table 3 serum bilirubin levels in relation to etiology of neonatal hyperbilirubinemia

\begin{tabular}{|c|c|c|c|c|c|}
\hline Etiology & $\begin{array}{c}5-10 \\
\mathrm{mg} / \mathrm{dl}\end{array}$ & $\begin{array}{c}10.1- \\
15 \mathrm{mg} / \mathrm{dl}\end{array}$ & $\begin{array}{c}15.1-20 \\
\mathrm{mg} / \mathrm{dl}\end{array}$ & $\begin{array}{c}>20 \\
\mathrm{mg} / \mathrm{dl}\end{array}$ & $\begin{array}{c}\text { Mean } \pm \text { S.D } \\
\mathrm{mg} / \mathrm{dl}\end{array}$ \\
\hline Physiological & 45 & 32 & 0 & 0 & $10.09 \pm 2.20$ \\
\hline ABO Incompatability & 0 & 6 & 8 & 16 & $19.93 \pm 4.04$ \\
\hline Rh Incompatability & 0 & 0 & 5 & 7 & $21.56 \pm 4.33$ \\
\hline Cephalhematoma & 0 & 1 & 2 & 0 & $12.73 \pm 4.33$ \\
\hline G6PD deficiency & 0 & 0 & 2 & 5 & $22.72 \pm 5.1$ \\
\hline Idiopathic & 4 & 18 & 8 & 9 & $15.63 \pm 4.37$ \\
\hline
\end{tabular}

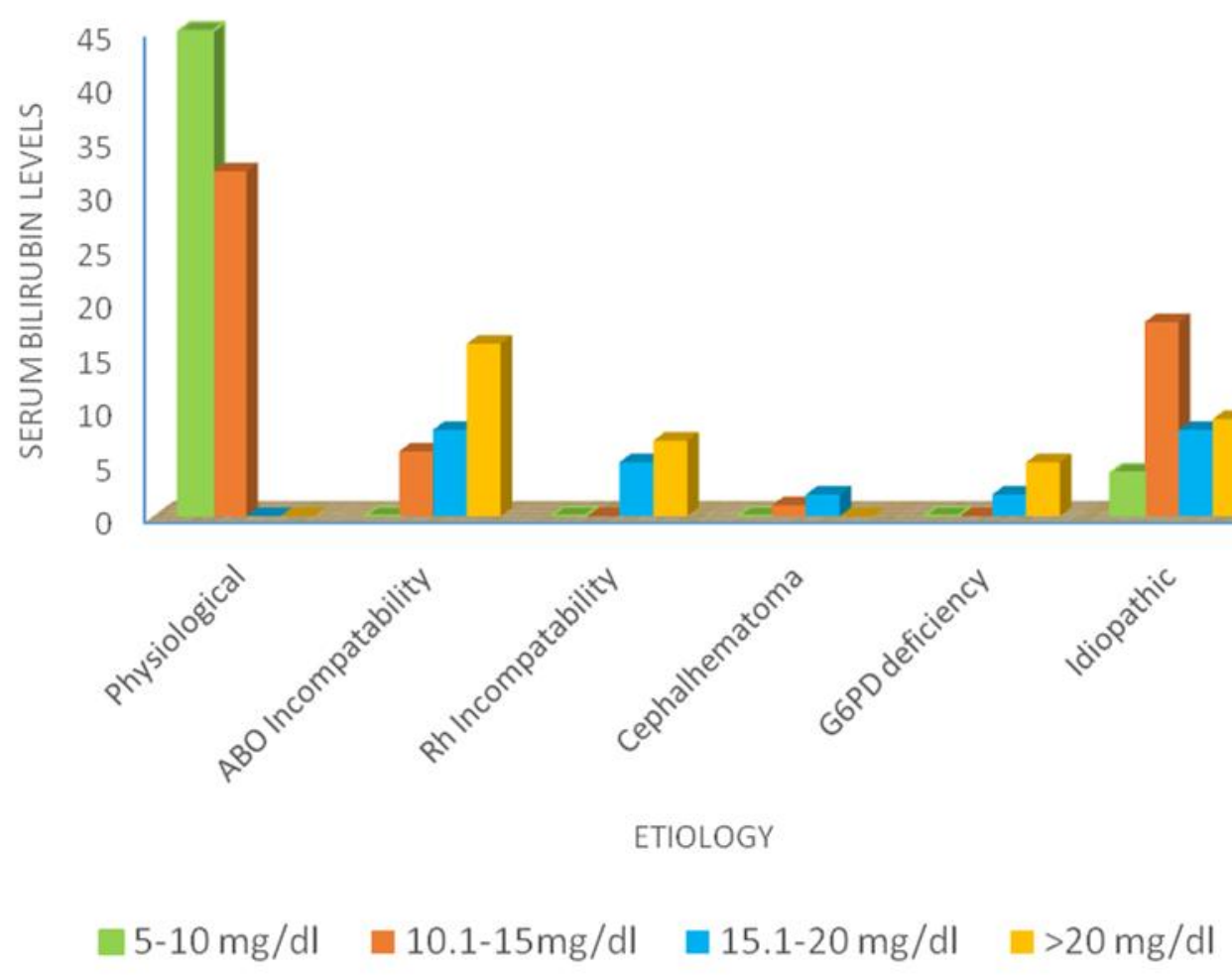

Figure-3 shows serum bilirubin levels in relation to etiology of neonatal hyperbilirubinemia

\section{Discussion}

In the present study, among jaundiced neonates, males constituted $115(68.45 \%)$ and females constituted $53(31.55 \%)$ in ratio of 2.1 : 1 , suggesting a male preponderance in cases of neonatal jaundice. This could be because of higher preponderance of males in the study $(\mathrm{M}: \mathrm{F}=115: 53)$ Male preponderance could also be explained by the fact that, male babies are given more attention than females and more commonly and earlier taken to health facilities by the parents.
Nassef et al conducted a study on 60 nonjaundiced neonates and 40 jaundiced cases with G6PDD. Out of the 40 jaundiced G6PD deficient cases, $62 \%$ were males and $37 \%$ were females [8]. Irshad $\mathrm{M}$ et al in their study observed an incidence of neonatal jaundice to be $70 \%$ in males and $30 \%$ in females [9].

In the present study, out of the 168 jaundiced newborns studied, 52 (32.11\%) neonates had a known pathological cause of jaundice.77 (45.83\%) neonates had physiological jaundice while in $39(23.21 \%)$ neonates the cause could not be ascertained, hence were grouped as idiopathic. 
Various studies reported that the frequency of G6PDD is more in north, than south India. The present study showed incidence of G6PDD to be 4.16\%. Pao et al[10] their study at New Delhi and Verma et al[11 ] in their study at Punjab showed an incidence of G6PDD to be $2.0 \%$ and $3.9 \%$ respectively, which is quite similar with the present study (4.16\%). Studies conducted by Suvitha Thilakarajan[12] at Bangalore reported an incidence of G6PDD to be $0.2 \%$ and $1 \%$ respectively which is less than our study, showing less incidence in Southern India.

Children with G6PDD can develop acute hemolytic crisis (induced hyperbilirubinemia) precipitated by particular foods or drugs causing significant morbidity. As primary prevention is not available, the only way to avoid morbidity is to recognize such children early in life and prevent exposure to triggering agents and drugs [13].

\section{G6PDD status and serum bilirubin levels}

In the present study we found 7 neonates $(4.16 \%)$ having G6PDD.Out of these, 3 cases were associated with another factor (i.e. prematurity ) which in itself is known to cause neonatal jaundice .In the remaining 4 cases, no cause other than G6PDD was found. All these 4 cases of isolated G6PDD also had significant hyperbilirubinemia. Mean serum bilirubin level in G6PDD was $22.72 \pm 5.1 \mathrm{mg} / \mathrm{dl}$, whereas in ABO incompatibility and $\mathrm{Rh}$ incompatability, it was $19.93 \pm 4.04 \mathrm{mg} / \mathrm{dl}$ and $21.56 \pm 4.33 \mathrm{mg} / \mathrm{dl}$ respectively. The lower levels in ABO incompatibility, suggests that there is milder hemolysis in $\mathrm{ABO}$ incompatibility as compared to G6PDD and $\mathrm{Rh}$ incompatibility. ABO incompatibility is usually reported as a milder disease in comparison to $\mathrm{Rh}$ disease[14].

\section{G6PD status by day of appearance of jaundice}

Amongst the G6PD deficient infants in our study the mean day of appearance of jaundice was $2.00 \pm 0.98$, and the difference was not found to be statistically significant ( $\mathrm{P}$ value $>0.05$ ) when compared to those neonates who had $\mathrm{ABO}$ and
Rh Incompatability, with $\mathrm{P}$ value being $(\mathrm{P}=0.41)$ and $(\mathrm{P}=0.08)$ respectively. In other causes like Physiological, Idiopathic, and Cephalhematoma the difference in the day of appearance of jaundice was statistically significant. A similar incidence of day of appearance of jaundice has been reported i.e. the onset on $2^{\text {nd }}$ day of life by Omran AA [15]. Mondal $\mathrm{M}$ et al in their study found the mean age of appearance of jaundice to be 70.54 hrs( i.e. Day 3)[16].

\section{Distribution of cases with G6PDD}

\section{Male to female ratio}

Various studies have reported varying incidence of G6PDD in males and females. But in our study, only males had G6PDD.This data is comparable with the study, which was conducted by Kumar K et al in 205 neonates at Aga Khan University Hospital, Karachi, Pakistan in 2010 [17]. Male preponderance is because of the fact that inheritance pattern in G6PDD is $\mathrm{X}$ linked. Therefore males suffer from the effect of deficiency and females are the carriers. However homozygous female with G6PDD can present clinically[18]. Kaur etal reported the incidence of G6PDD in this study was found to be 1 in 112 $(0.89 \%)$ with a higher prevalence in males than females in Chandigarh, India which was true for the present study also[19].Pao $\mathrm{M}$ et al conducted a retrospective hospital based study among 2479 neonates and observed G6PDD incidence to be $2 \%$. In males, incidence was $2.83 \%$ and in females incidence was $1.05 \%[10]$.Kumar $\mathrm{P}$ et al performed a meta-analysis in both fixed and random effect models. A total of 72 studies with a total sample size of 38,565 and 2,623 G6PD deficient subjects were included in the metaanalysis and concluded the overall magnitude of the frequency of G6PDD to be $(8.5 \%)$ in the Indian population[23].

\section{G6PD status by birth weight}

2 out of 7 G6PD deficient neonates were Low birth weight(LBW) babies i.e weighing less than $2.5 \mathrm{~kg}$ and 01 baby was very low birth weight(VLBW) i.e. weighing $<1.5 \mathrm{~kg}$. Narang et 
al in a similar study on neonatal jaundice in VLBW babies found that G6PDD was the commonest cause $(12.1 \%)$ of jaundice among them[20].

\section{G6PD status by gestational age}

4 Out of 7 G6PD deficient cases in our study were term and 3 were preterm neonates. In our study more cases i.e. $4(57.1 \%)$ cases were term G6PD deficient neonates and 3(42.8\%) were preterm.). Kumar $\mathrm{K}$ et al in a similar study which was conducted in Pakistan, observed (17.6\%) preterm and $(82.4 \%)$ term G6PD deficient neonates, which are similar with our observations regarding incidence in preterm/ term babies[17].

\section{G6PD status by hemoglobin levels}

In present study, 5 G6PD deficient neonates had hemoglobin level between 14-16 gm/dl, 1 neonate between $12-14 \mathrm{gm} / \mathrm{dl}$ and 1 neonate $<12 \mathrm{gm} / \mathrm{dl}$. Hence only 1 was severely anemic A similar value i.e more than half of the G6PD deficient had hemoglobin levels more than $14 \mathrm{gm} / \mathrm{dl}$ has been reported by Omran et al[15].

Madan et al found a mean hemoglobin level of $14.7 \mathrm{gm} / \mathrm{dl}$ in the G6PD deficient group[20].These findings suggest that hemolysis is not the main determinant of jaundice in G6PD deficient groups , as reported by Hiali et al, as they did not found much significant difference between reticulocyte count and hemoglobin levels between G6PD deficient and non deficient icteric neonates in their study [24].On the contrary, other study groups supports the concept of hemolysis in G6PDD [25].

Regarding outcome of G6PD deficient cases, all G6PD cases in the present study recovered completely, as they were brought early, before any neurological damage could happen.

\section{Conclusion}

G6PDD is one of the common causes of neonatal jaundice predominantly in males. The babies suffering from G6PDD can present with jaundice earlier than the other etiologies. There is no difference in distribution of G6PDD in preterm and term babies. G6PDD produces most severe form of neonatal jaundice with higher hemoglobin levels and significant hyperbilirubinemia. Total bilirubin levels in G6PDD cases is highest as compared to other etiological factors of neonatal jaundice. G6PDD leads to anisopoikilocytosis which signifies an ongoing hemolysis. From our study we suggest that screening for G6PDD should be included in all neonatal screening programmes,so as to prevent complications like bilirubin encephalopathy.

\section{Acknowledgements}

We thank Mr. Sunil Rajkot for his help in statistical analysis of this study.

\section{Financial support: Nil}

\section{Conflict of interest: Nil}

\section{References}

1. Macmohan JR, Stevenson DK, Oski FA. Physiologic Jaundice. In William TH, Robert AB, eds. Avery's diseases of the newborn, 7th ed. Singapore; Harcourt Asia private limited, 1998: 1003.

2. Alastair JJ, Wood Md. neonatal hyperbilirubinemia. N Engl J Med.2001; 344(8):581-9.

3. Mohanty D, Mukherjee MB, Colah RB. Glucose-6-phosphate dehydrogenase deficiency in India. Indian journal of pediatrics. 2004 ;71:525-9. 
4. Akkani EO, Oseni BSA, Agbona VO, Tijani BA, Tosan E, Fakunie EE, Mabayoje VO. Glucose-6-phospahte dehydrogenase deficiency in blood donors and jaundiced neonates in Osogbo, Nigeria, Journal of Medical Laboratory and diagnosis. 2010; 1(1):1-4.

5. Farhud DD, Yazdanpanah L. Glucose-6phosphate dehydrogenase deficiency . Iranian J of public health. 2008;37(4): 1-18.

6. Mondal M, Datta AK, Mandal S, Das PK. Study of glucose-6-phospahte dehydrogenase deficiency in neonatal jaundice. Journal of pharmacy and Biological Sciences. 2012;1 (5):30-6.

7. Nair H. Neonatal screening program for G6PD deficiency in India: need and feasibility. Indian Pediatrics. 2009;46: 1045-8.

8. Naseef YE, Fathy HA, Ali A, Hamed MA, Fath GA. Evaluation Of G6PD Activity and antioxidant status in jaundiced Egyptian neonates. International Journal of Medicine and Medical sciences. 2013; 5(12): 550-9.

9. Irshad M, Mohammad A, Hussain M, Khan B, Ali N, Ahmad A et al. Prevalence of Rhesus Type And ABO incompatability in Jaundiced Neonates. JPMI. 2011; 25 (3) : 233 - 9.

10. Pao M, Kulkarni A, Guppta V, Kaul S, Balan S. Neonatal Screening For Glucose 6 Phosphate Dehydrogenase Deficiency: Indian Journal of Paediatrics. 2005;72(10) : 835-7.

11. Verma M, Singla D, Crowell SB. G6PD deficiency in neonates. A Prospective study. Indian J Pediatrics. 1990; 57(3): 385-8.

12. Thilakarajan S, Niveditha SR, Keshavamurthy. G-6PD Screening in Neonatal Hyperbilirubinemia. Indian Journal of Neonatal Medicine and Research. 2015; 3(1): 1-6.

13. Bubp J, Jen M, Matuszewski K. Caring for Glucose-6-Phosphate Dehydrogenase (G6PD)-Deficient Patients: Implications for Pharmacy. P\&T. 2015;40 (9):572-4.

14. Clarke CA. Scientific basis of clinical practise: practical effects of blood group incompatability between mother and fetus. $\mathrm{Br}$ Med J. 1972;2:90-5.
15. Omran AA, Ghazal FA, Gupta S, John TB. Glucose 6 phosphate dehydrogenase deficiency and neonatal jaundice in Al-Hofuf Area. Annual of Saudi Medicine 1998; 19:156-8.

16. Mondal M, Datta AK, Mandal S, Das PK. Study of Glucose -6-Phosphate Dehydrogenase Deficiency In Neonatal Jaundice. IOSR Journal of Pharmacy and Biological Sciences. 2012;1(5): 30-6.

17. Kumar K, Sohaila A, Tikmani SS, Khan IA, And Zafar A. Screening For G6PD Deficiency Among Neonates With Neonatal Jaundice Admitted To Tertiary Care Center: A Need In Disguise. Journal of the College of Physicians and Surgeons Pakistan. 2015;25 (8): 625-6.

18. Beutler E. G6PD deficiency. Blood 1994;84:3613-36.

19. Kaur G, Srivastav J, Jain S, Chawla D,. Chavan BS, Atwal R, Randhawa G. Preliminary Report on Neonatal Screening for Congenital Hypothyroidism, Congenital Adrenal Hyperplasia and Glucose-6Phosphate Dehydrogenase Deficiency: A Chandigarh Experience. Indian J Pediatr.2010;77:969-73.

20. Narang A. Kumar P, Kumar R, Neonatal jaundice in very low birth weight babies. Indian J Pediatr. 2001; 6(4):307-9.

21. Nishi M, Jayant D, Talwar N, Bhargava SK, Sood SK. Incidence of G6PD deficiency in a hospital population of Delhi. Indian J Med Res. 1981;734:25-9.

22. Khode K. Incidence of G6PD deficiency in OPD cases in a Hospital: Journal of Indian academy of clinical medicine. 2001; 2(4): 349-50.

23. Kumar P, Yadav U, Rai V: Prevalence of glucose-6-phosphate dehydrogenase deficiency in India: An updated meta-analysis, The Egyptian Journal of Medical Human Genetics. 2016; 17, 295-302.

24. Al-Hiali SJ, Al-Diwan JK, AlJanabi M.Glucose $6 \quad$ Phosphate DehydrogenaseDeficiency Among Neonates With Hyperbilirubinemia In Western Iraq. J Fac Med Baghdad. 2000;50(4): 431-4. 
25. Seidman DS, Shiloh M, Stevenson DK, Verman HJ, Paz I, Gale R. Role of hemolysis in neonatal jaundice associated with glucose 6 phosphate dehydrogenase deficiency. J Pediatr, 1995;127:804-6.

\begin{tabular}{|c|l|}
\hline \multicolumn{2}{|c|}{ Access this Article in Online } \\
\hline & Website: \\
\hline & www.ijcrims.com \\
\hline Quick Response Code & Subject: \\
\hline
\end{tabular}

How to cite this article:

Karnail Singh, Palwinder Singh, Munish Sagar,Vijay Mehra, N.S.Neki. (2017). Incidence, etiological risk factors and outcome of glucose-6 phosphate dehydrogenase deficiency (G6PDD) among neonates presenting with hyperbilirubinemia in tertiary care hospital, Punjab. Int. J. Curr. Res. Med. Sci. 3(3): 62-71.

DOI: http://dx.doi.org/10.22192/ijcrms.2017.03.03.008 